\title{
Forum
}

\section{Focusing on corruption: a reply to Ferraro and Katzner}

\author{
Matthew J. Walpole and Robert J. Smith
}

Corruption is a complex phenomenon with various confounding effects and, in their separate replies, both Ferraro (2005) and Katzner (2005) note that in some cases corruption may have short- and long-term benefits for conservation by limiting extractive and destructive development activities. We agree, and we also acknowledge that better governance does not necessarily lead to better conservation; a cursory look at Conservation International's biodiversity hotspots (Conservation Interational, 2005) shows that these threatened regions occur in countries with both high and low governance levels.

However, in emphasizing these two points, Katzner makes a number of assertions that threaten to confuse the debate. For example, he suggests that less corrupt countries are less biodiverse because they are more efficient consumers of natural resources. However, his attempt to illustrate this with an analysis of European farmland bird declines is somewhat over-simplistic. As Ferraro points out, testing basic statistical correlations with weak theoretical underpinning tells us little about what is really driving change and is of little use when action is needed. In the case of European bird declines, perverse agricultural incentives are likely to play a significant role (Berendse et al., 2004) but, along with many other potential explanatory factors, they are not considered in Katzner's analysis. Furthermore, Katzner's assertion that corrupt countries are not organized enough to exert wholesale ecosystem destruction is contradicted by many examples, including Indonesia, which suffers from corruption yet is still capable of destroying its forest resources at a rapid rate (Jepson et al., 2001). Rather than operating in an organizational vacuum, corruption needs systems to subvert.

Moreover, Katzner's interpretation of the more widespread negative correlation between national governance levels and bird and mammal species richness seems equally problematic. There is no evidence that this is a causal relationship. Instead, the same pattern could

Matthew J. Walpole (Corresponding author) Fauna \& Flora International, Great Eastern House, Tenison Road, Cambridge, CB1 2TT, UK.

E-mail matthew.walpole@fauna-flora.org

Robert J. Smith Durrell Institute of Conservation and Ecology, University of Kent, Canterbury, Kent, CT2 7NS, UK.

Received 6 April 2005. Accepted 11 April 2005. be explained by the well documented links between species richness and latitude (Lyons \& Willig, 2002), as corrupt countries tend to be found in the tropics. For example, a comparison of tropical Singapore with temperate Sweden reveals that both had the same Corruption Perception Index score in 2002, whilst the former's species richness is four times higher (Transparency International, 2002a; Smith et al., 2003). Our reason for stressing the negative relationship between governance and species richness was not to suggest that one drives the other. Instead, we sought to highlight that external funds for biodiversity conservation are more likely to be spent in corrupt countries, where misappropriation could be more of a threat.

Katzner extends his line of argument to assert that corruption and its impacts are driven by less corrupt, developed nations through their demand for export resources and their economic influence, and that the focus of attention should be moved away from corrupt nations and towards countries in Europe and North America. This too is problematic, as it suggests that conservationists in the West should not support the efforts of developing nations to reduce corruption levels until they address over-consumption in their own countries. Addressing this over-consumption is obviously vital, but these problems are well known and are the focus of many conservation campaigns. Moreover, changing these consumer patterns is a long-term challenge, whereas our focus is on the potential benefits of reducing the impact of corruption on conservation project success, which could have much more immediate impacts. Both of these can and should be legitimate goals for conservationists, and it would be better to address this openly than to attempt to hide one behind the other.

In addition, Katzner places most of the blame for bribery and corruption at the doorstep of well-governed capitalist systems. Yet many nations, well-governed or otherwise, contain individuals and companies rich enough to pay bribes, and these attempts are more likely to succeed in countries with low governance levels. It is also worth noting that foreign governments in countries with low governance levels are more likely to offer bribes to companies in emerging markets, and that local governments tend to bribe the most (Transparency International, 2002b). It is well known that corruption is rarely restricted to one aspect of a supply chain and it is somewhat condescending to accuse western conservationists of failing to recognise this, but it seems unlikely that the 
only effective way of addressing problems of illegal trade is to focus on consumers in the West.

We all agree that corruption is far more complex than simple theories and analyses give it credit for, and that it needs more attention. We also agree that strategies such as increasing civil servant wages in poor, corrupt countries are unlikely to work in all contexts or in isolation. This is why we strongly support Ferraro's suggestion that this is not an issue that biologists can or should tackle alone. Conservation cannot continue to be viewed solely as a branch of biological sciences because technical solutions grounded in ecology and animal behaviour will only ever answer a small set of conservation questions. Whether one needs economists and social scientists working alongside biologists, or a new breed of integrated conservation scientist with academic grounding in a range of disciplines, is a moot point. The latter is beginning to develop as conservation becomes a discipline in its own right, but its links to the biological sciences remain overbearing in many institutions of higher education.

This means that we have not yet reached the point where conservation is a truly integrated and multidisciplinary field. But even if it were, a paucity of suitable data makes it difficult to carry out detailed and rigorous analyses (Dietz \& Adger, 2003). That aside, there is a clear need to work harder to overcome the barriers between traditional disciplines, and encourage productive collaboration, rather than settle for mutual miscomprehension (Campbell, 2005). In that regard, we hope that the debate over the role of corruption in conservation will stimulate new research and new partnerships.

\section{References}

Berendse, F., Chamberlain, D., Kleijn, D. \& Schekkerman, H. (2004) Declining biodiversity in agricultural landscapes and the effectiveness of agri-environment schemes. Ambio, 33, 499-502.

Campbell, L.M. (2005) Overcoming obstacles to interdisciplinary research. Conservation Biology, 19, 574-577.

Conservation International (2005) Biodiversity Hotspots. Http:/ / www.biodiversityhotspots.org [accessed 11 April 2005].

Dietz, S. \& Adger, W.N. (2003) Economic growth, biodiversity loss and conservation effort. Journal of Environmental Management, 68, 23-35.

Ferraro, P. (2005) Corruption and conservation: the need for empirical analyses. A response to Smith and Walpole. Oryx, 39, 257-259.

Jepson, P., Jarvie, J.K., MacKinnon, K. \& Monk, K.A. (2001) The end for Indonesia's lowland forests? Science, 292, 859.

Katzner, T. (2005) Corruption - a double-edged sword for conservation? A response to Smith \& Walpole. Oryx, 39, 260-262.

Lyons, S.K. \& Willig, M.R. (2002) Species richness, latitude, and scale-sensitivity. Ecology, 83, 47-58.

Smith, R.J., Muir, R.D.J., Walpole, M.J., Balmford, A. \& Leader-Williams, N. (2003) Governance and the loss of biodiversity. Nature, 426, 67-70.

Transparency International (2002a) Transparency International Bribe Payers Index 2002. Http:/ / www.transparency.org [accessed 11 April 2005].

Transparency International (2002b) Transparency International Corruption Perceptions Index 2002. Http:/ /

www.transparency.org [accessed 11 April 2005]. 